\title{
Artículo
}

\section{Impacto de las TIC en el modelo de organización electoral mexicano*}

\author{
Roberto López Pérez**
}

RESUMEN: El presente artículo tiene como objetivo dar cuenta e invitar a la reflexión sobre los cambios exponenciales propios de los tiempos que corren generados por el uso de las nuevas tecnologías de la información y la comunicación (TIC), en prácticamente todos los ámbitos de la sociedad, los cuales han tenido diversos efectos en la aldea global, incluyendo el jurídico, especialmente el que regula el modelo de organización electoral de nuestro país; efectos -positivos y negativos- que pueden llegar a condicionar el ejercicio efectivo de los derechos políticoelectorales y los derechos con los cuales se vinculan, circunstancia por la que se estima tales efectos deben ser conocidos, comprendidos y regulados, oportuna y formalmente, con la finalidad de garantizar el ejercicio eficaz de los derechos referidos.
ABSTRACT: This article aims to give an account and invite reflection on the exponential changes of the times that are generated by the use of new information and communication technologies (ICT), in virtually all areas of society, which have had various effects on the global village, including the legal one, especially the one that regulates our country's electoral organization model; effects - positive and negative - that may affect the effective exercise of political-electoral rights and the rights with which they are linked, a circumstance for which such effects are estimated should be known, understood and regulated, timely and formally, with the purpose of guaranteeing the effective exercise of the aforementioned rights.

Keyswords: TIC'S, Political-electoral rights,

Palabras clave: TIC, Derechos político- Electoral Organization, Internet, Social electorales, Organización Electoral, Internet, networks.

Redes Sociales.

SUMARIO: Introducción. 1. El uso de las TIC en el modelo de organización electoral mexicano. 2. Algunos cuestionamientos en relación a los efectos que generan el uso de las TIC en el ejercicio de los derechos político-electorales y los derechos con ellos vinculados.

\footnotetext{
* Artículo recibido el 30 de septiembre de 2019 y aceptado para su publicación el 6 de enero de 2020.

** Licenciado en Derecho y Maestro en Derecho con área de especialización en Derecho Constitucional y Administrativo por la Universidad Veracruzana, donde también curso el Doctorado en Derecho Público. Especialista en Justicia Electoral por el Centro de Capacitación Judicial Electoral del Tribunal Electoral del Poder Judicial de la Federación. Consejero Electoral del Organismo Público Local Electoral del Estado de Veracruz.
} 


\section{López R. / Impacto de las TIC en el modelo de organización electoral mexicano}

3. Aproximaciones de respuestas a los cuestionamientos planteados. A manera de conclusiones. Fuentes de consulta.

\section{Introducción}

Resulta innegable que el mundo está cambiando como nunca antes en la historia de la humanidad. Hemos sido testigos del tránsito de los cambios lineales, a los que estábamos acostumbrados, hacia los cambios exponenciales de los tiempos que corren; estos últimos más visibles en el contexto mundial a partir de la crisis financiera de 2008-2009 (quiebra Lehman Brothers, Plan Paulson, Eurogrupo y su plan de ayuda a bancos, nuevas políticas del G20, entre otros factores) y que, invariablemente, han tenido diversos efectos en la aldea global.

Uno de esos cambios lo constituye el uso de nuevas tecnologías (inteligencia artificial, autonomía y automatización) en prácticamente todas las áreas de la actividad humana, las cuales, haciendo un esfuerzo de síntesis, permiten la realización de múltiples labores, públicas y privadas, de forma más eficiente y rápida, minimizando costos y maximizando utilidades; es decir, facilitan y mejoran la vida humana.

Así, por referir algunos ejemplos recientes, hoy observamos a Walmart realizando inventarios mediante robots; a Amazon usando inteligencia artificial en tareas de almacenaje; y a DHL empleando Cobots -robots colaborativos- en su logística. Asimismo, hoy sería casi impensable nuestra vida diaria sin el uso de la internet, teléfonos inteligentes y sus múltiples aplicaciones, poderosos ordenadores, la biotecnología o el sistema de navegación global vía satélite (GPS).

Indudablemente el futuro nos ha alcanzado y es evidente que las nuevas tecnologías llegaron para quedarse como componente inseparable de nuestro entorno económico, político, jurídico, cultural y social. Ellas han implicado, ni más ni menos, una nueva forma de relacionarnos y de vivir en sociedad, con profundas transformaciones apenas comprensibles, dada la rapidez con la que han pasado a formar parte de nuestro día a día.

En ese contexto, como lo refiere John Keane, el mundo atraviesa por una segunda era de la revolución de las máquinas, por una transformación mucho más global, arraigada y absoluta debido a la aplicación de la inteligencia artificial (Al) y los robots "inteligentes" en cada vez más esferas de la vida cotidiana; un momento tecnopolítico en donde existe como asignatura pendiente una importante discusión sobre la democracia. ${ }^{1} \mathrm{Y}$ una revolución de tal dimensión no puede ser obviada en ninguna ciencia, menos en la jurídica, porque como lo refiere Hacking invocando la obra de Kuhn, la revolución destruye la continuidad y progresa en dirección opuesta a las concepciones previas del mundo. ${ }^{2}$

\footnotetext{
${ }^{1}$ Cfr. Keane, J. (2019). Letras Libres, "La nueva era de la revolución de las máquinas", trad. de Ricardo Dudda, México, 01 de abril de 2019, consultable en el link https://www.letraslibres.com/espana-mexico/revista/lanueva-era-la-revolucion-las-maquinas

${ }^{2}$ Véase Hacking, I. (2013). La estructura de las revoluciones científicas, "Ensayo preliminar", en Kuhn, Thomas S., 4a. ed., trad. de Carlos Solís Santos, México, Fondo de Cultura Económica, pp. 45 y 46.
} 


\section{López R. / Impacto de las TIC en el modelo de organización electoral mexicano}

El ámbito jurídico, específicamente el rubro de los derechos fundamentales de naturaleza político-electoral, no ha sido ajeno a los impactos de los cambios profundos que se comentan.

En el año 2017 el gobierno de Arabia Saudita concedió ciudadanía a un robot humanoide llamada Sophia, convirtiéndose en el primer androide del mundo en adquirirla ${ }^{3}$ con los derechos que ello implica, tales como la adquisición de un pasaporte, desencadenando una serie de efectos a los que el reino saudí aun hace frente, sobre todo, ante la limitación de dichos derechos que sufren las mujeres de ese país (barreras culturales e institucionales, ausencia de instrumentos que les permitan el ejercicio al voto y escasa participación política, por referir algunas) quienes, paradójicamente, se colocan en una situación de desventaja frente al robot, puesto que, por ejemplo, deben conseguir previamente un permiso de su esposo o padre para obtener el pasaporte o viajar al extranjero (restricción que se vigila con tecnología: aplicación Absher).

Incluso, para el ejercicio del derecho político-electoral en su aspecto activo, la tecnología, mediante el voto electrónico, se ha empleado exitosamente en países tales como la India, Brasil, Paraguay, Suiza, Estonia, Emiratos Árabes y Venezuela. ${ }^{4}$

En nuestro país, el uso de las tecnologías de la información y comunicación como medio para el ejercicio de los derechos político-electorales (votar, ser votado, asociación, afiliación e integración de autoridades electorales) y los derechos con los que se vinculan (petición, información, reunión, así como libertad de expresión y difusión de ideas), ha sido práctica frecuente de las instituciones electorales, facilitando considerablemente la materialización de sus atribuciones constitucionales y legales, tal como se advierte en el apartado 1.

De ahí la necesidad y pertinencia de analizar los efectos positivos y negativos de dichas tecnologías como acción ineludible para garantizar la continuidad de las sociedades democráticas en razón del impacto que generan hacia las reglas de la democracia misma, esto es, las reglas de convivencia en comunidad, de acceso y distribución del poder público, de los pesos y los contrapesos institucionales, pero sobre todo, del ejercicio efectivo de los derechos político-electorales y de los derechos con ellos vinculados, ámbito éste al que circunscribe el presente artículo con énfasis en nuestro modelo de organización electoral, al que se entiende como:

(...) la arquitectura institucional que define a las instituciones cuya encomienda principal se dirige a la garantía del ejercicio de los derechos político-electorales de los ciudadanos, principalmente el derecho

\footnotetext{
${ }^{3}$ Al respecto, véase BBC Mundo, "Sophia, la robot que tiene más derechos que las mujeres en Arabia Saudita", publicado el 30 de octubre de 2017, visible en el link: https://www.bbc.com/mundo/noticias-41803576

${ }^{4}$ Conforme a datos de IDEA Internacional (2017), del total de 145 países donde ha hecho investigación, el 21\% emplea tecnología para la identificación de electores en mesas de votación. Al respecto, véase PARAMETRÍA, INVESTIGACIÓN ESTRATÉGICA, ANÁLISIS DE OPINIÓN Y MERCADO, “Apoyan voto electrónico", consultable en el link http://www.parametria.com.mx/carta_parametrica.php?cp=5112 Sobre el particular, es de destacarse que, en nuestro país, también existen casos exitosos de la implementación del voto electrónico a nivel subnacional, tal es el caso de entidades como Coahuila, Jalisco y el otrora Distrito Federal. Cfr. DíAZ NARANJO, Fernando, La Silla Rota, "Fortalezas y debilidades de la votación electrónica", edición del 1 de julio de 2019, visible en el link https://lasillarota.com/opinion/columnas/fortalezas-y-debilidades-de-la-votacionelectronica/294176
} 
López R. / Impacto de las TIC en el modelo de organización electoral mexicano

a votar y ser votado, a través de actividades de organización o gestión del proceso electoral, mecanismos de control de la regularidad jurídica de sus actos, o de justicia electoral, e instrumentos de persecución de conductas que vulneran la libertad y autenticidad del sufragio. ${ }^{5}$

\section{El uso de las TIC en el modelo de organización electoral mexicano}

Enunciativamente y a modo de ejemplo, en las líneas siguientes se señalan las principales TIC utilizadas en nuestro modelo de organización electoral nacional para el ejercicio de derechos político-electorales y los derechos con ellos vinculados.

Inicialmente, en la actualización y depuración del padrón electoral se echa mano de la tecnología de biométricos; asimismo, se recurre a los avances tecnológicos para emitir la credencial para votar con altos estándares de seguridad y confiabilidad (huellas dactilares digitales, holograma, fotografías digitales, código de barras con filtro infrarrojo, micro impresión de datos, dispositivos ópticos variables, fondo de seguridad de alta resolución, tecnología anticopias, códigos bidimensionales $Q R$ ) documento que, por tales características, representa el medio de identificación oficial más utilizado a nivel nacional.

En similar sentido, se usan aplicaciones móviles para facilitar el registro en la Lista Nominal de mexicanos residentes en el extranjero, así como para promover iniciativas ciudadanas. También se emplean para la afiliación de ciudadanas y ciudadanos que brindan su apoyo a organizaciones que pretendan constituirse como partido político; así como para la captación de apoyos ciudadanos a aspirantes a candidaturas independientes.

De igual manera, se han diseñado sistemas informáticos que brindan información oportuna y veraz sobre el desarrollo de las jornadas electorales (SIJE, operado con dispositivos móviles); que permiten publicar imágenes y datos electorales preliminares (PREP, apoyado en dispositivos móviles); y dar conocer, a pocas horas de concluida una elección, tendencias de votación confiables (conteos rápidos); así como para gestionar el control y seguimiento de resultados oficiales (sistemas de cómputos); todo lo cual facilita la realización de los principios de certeza, objetividad y máxima publicidad que deben revestir el ejercicio de la función electoral. Incluso, a través de la internet, el voto electrónico será, próximamente, una realidad para las y los mexicanos residentes en el extranjero, aplicable para procesos electorales federales y locales. ${ }^{6}$

Además, las redes sociales se emplean como herramientas para maximizar los derechos político-electorales, tal como ocurrió durante el proceso electoral concurrente 2017-2018 en el que, el Instituto Nacional Electoral (INE), fomentó la emisión del voto libre e

\footnotetext{
${ }^{5}$ Astudillo Reyes, C. I. (2019). Estudios Electorales, México, Tirant Lo Blanch, p. 209.

${ }^{6}$ Al respecto, el 8 de mayo de 2019, por Acuerdo INE/CG243/2019, el INE aprobó los Lineamientos que establecen las características generales que debe cumplir el Sistema del voto electrónico por Internet para las y los mexicanos residentes en el extranjero. Cabe precisar que, en términos del citado acuerdo, dicho Sistema se utilizará hasta que el Consejo General de la citada autoridad electoral nacional determine el uso de la modalidad del voto electrónico de referencia. Más recientemente, el 18 de septiembre de 2019, mediante proveído INE/CG432/2019, dicha autoridad electoral aprobó Los lineamientos para la auditoría al sistema del voto electrónico por internet. Los referidos acuerdos, obran disponibles en el repositorio documental del INE, consultables los links https://repositoriodocumental.ine.mx/xmlui/discover?query=INE\%2FCG243\%2F2019\&scope=\%2F $\quad$ y https://repositoriodocumental.ine.mx/xmlui/handle/123456789/112647
} 
informado, la participación ciudadana en las elecciones, mejores prácticas para la comunicación política y la integridad de dicho proceso, a través de la celebración de convenios de colaboración con Facebook (el INE es la primera autoridad en el mundo en firmar un convenio de este tipo $)^{7}$ y Google, ${ }^{8}$ así como la suscripción de un memorándum de entendimiento con Twitter. ${ }^{9}$

En tales circunstancias, resulta incuestionable que el uso de las tecnologías de la información y la comunicación como herramientas para facilitar el ejercicio de los derechos político-electorales, así como los derechos fundamentales con ellos relacionados, han generado efectos positivos que se han hecho extensivos a la labor de las instituciones electorales maximizando también el empleo de recursos en dicho ámbito.

\section{Algunos cuestionamientos en relación a los efectos que generan el uso de las TIC en el ejercicio de los derechos político-electorales y los derechos con ellos vinculados}

Ciertamente hay consciencia sobre el papel fundamental que las TIC aportan en la recreación de nuestra democracia; tan es así que, al día de hoy, desde la propia voz de integrantes de autoridades electorales nacionales ${ }^{10}$ y desde el ámbito legislativo se impulsa

\footnotetext{
${ }^{7}$ Este hecho resulta especialmente relevante en razón de que más de 80 millones de mexicanos están en esta red social para construir conexiones significativas con sus comunidades y con los temas más relevantes para ellos, incluyendo conversaciones políticas. Cfr. Instituto Nacional Electoral, Central Electoral, "Facebook e INE anuncian colaboración para elecciones", publicado el 5 de febrero de 2018, consultable en el link https://centralelectoral.ine.mx/2018/02/05/facebook-e-ine-anuncian-colaboracion-para-elecciones/. Por su parte, Twitter fue el escenario que millones de mexicanos eligieron para expresar sus opiniones registrándose, entre el 19 de marzo y el 19 de junio de 2018, un total de 28.2 millones de tuits. Al respecto véase EL ECONOMISTA, "7 acciones de Twitter para las elecciones del 1 de julio en México", edición digital del 26 de junio de 2018, visible en el link https://www.eleconomista.com.mx/tecnologia/7-acciones-de-Twitter-paralas-elecciones-del-1-de-julio-en-Mexico-20180626-0066.html

${ }^{8}$ Entre otros beneficios de este convenio, destacan el ofrecimiento de servicio a los votantes para ubicar su casilla vía Google Maps y el de orientación sobre cómo votar; y hacer accesible en el buscador la información pública disponible sobre los candidatos y sus propuestas. Véase Instituto Nacional Electoral, Central Electoral, "Colaboran INE y Google para mantener informada a la ciudadanía sobre el Proceso Electoral", publicado el 8 de abril de 2018, disponible en el link https://centralelectoral.ine.mx/2018/04/08/colaboran-ine-y-googlepara-mantener-informada-la-ciudadania-sobre-el-proceso-electoral/

9 Tanto twitter como Facebook son de capital relevancia para informar. Son esas dos redes sociales, principalmente, a quienes acuden las cadenas de televisión de noticias, tanto nacionales como en red, sabedoras de su velocidad y preponderancia social. Véase a Garita Quesada, M. E. "Las redes sociales como instrumentos de poder: su influencia en la toma de decisiones", en línea, consultable en el link http://www.kerwa.ucr.ac.cr/bitstream/handle/10669/73325/Art\%C3\%ADculo-Las\%20redes\%20socialessu\%20poder\%20influenciador\%20en\%20la\%20toma\%20de\%20desiciones\%20.pdf?sequence=1\&isAllowed=y ${ }^{10}$ Es el caso del Consejero del INE, Marco Antonio Baños Martínez, quien llamó al Poder Legislativo a definir el uso del voto electrónico. Véase el DIARIO DIGITAL INFORMATE.COM.MX, "Definir uso de voto electrónico, llama Consejero Electoral a Legislativo", edición del 28 de febrero de 2018, visible en el link https://www.informate.com.mx/nacionales/definir-uso-de-voto-electronico-llama-consejero-electoral-alegislativo.html
} 


\section{López R./ Impacto de las TIC en el modelo de organización electoral mexicano}

la implementación del voto electrónico en México. ${ }^{11}$ Es más, apenas en diciembre de 2019, el INE aprobó una prueba piloto de urna electrónica, con votos vinculantes, para las próximas elecciones de Hidalgo y Coahuila que tendrán verificativo en $2020 .{ }^{12}$

Vista en contexto, la tecnología puede servir para preservar y robustecer nuestra democracia constitucional; o, al menos, para contrarrestar el desencanto que enfrenta en los tiempos que corren. Entre otras cuestiones, se habla de un malestar generalizado de la ciudadanía con los resultados de la democracia; de la incapacidad de respuesta de las instituciones a los grandes problemas estructurales; de la debilidad del estado de derecho; de la desconfianza generalizada hacia las instituciones; y del bajo aprecio a los partidos políticos. ${ }^{13}$

En todo caso, deben considerarse atinadas acotaciones tales como las que precisan que, para las nuevas generaciones, el acceso a internet se trata de un derecho, no de un privilegio, que marca un cambio electoral relevante; de hecho, hoy en día, en la competencia electoral, el internet y las redes sociales son imposibles de ignorar. ${ }^{14}$ Tales aseveraciones no son menores si consideramos que, para el año 2018, en nuestro país, había 82.7 millones de usuarios de la red; y que, el acceso a las redes sociales, con un $82 \%$, encabezaba las actividades más recurrentes para las que se utiliza. ${ }^{15}$

Sin embargo, ante dichos cambios que generan las nuevas tecnologías, es preciso plantearse los siguientes cuestionamientos: ¿Los efectos del uso de las TIC pueden condicionar el ejercicio de los derechos político-electorales y los derechos fundamentales con los que se vinculan?; ¿Se implementan acciones para prever esos efectos, dirigidas a minimizar riesgos y robustecer el principio de certeza jurídica que exige el actual modelo electoral mexicano para el ejercicio de tales derechos?; y ¿Nuestra legislación actual es

\footnotetext{
11 Propuesta del grupo parlamentario del otrora Partido Encuentro Social. Véase CÁMARA DE DIPUTADOS, Gaceta Parlamentaria, año XXI, número 5116-II, 18 de septiembre de 2018, disponible en el link http://gaceta.diputados.gob.mx/Gaceta/64/2018/sep/20180918-II.htmI\#Iniciativa4

${ }^{12}$ Cfr. Instituto Nacional Electoral, Central Electoral, “Aprueba INE Lineamientos para el voto electrónico en elecciones de Coahuila e Hidalgo 2020", publicado el 16 de diciembre de 2019, consultable en el link https://centralelectoral.ine.mx/2019/12/16/aprueba-ine-lineamientos-voto-electronico-eleccionescoahuila-e-hidalgo-2020/

13 Véase Instituto Nacional Electoral, Estrategia Nacional de Cultura Cívica 2017-2013 (versión ejecutiva), México, 2016, pág. 9. De hecho, conforme al estudio sobre democracias en desarrollo elaborado por la Revista Británica The Economist, México se sitúa en la posición 71 a nivel mundial con 6.19 puntos, en contraste con países latinoamericanos tales como Uruguay (8.38 puntos) y Costa Rica (8.07 puntos), que figuran dentro de los 20 países del mundo con una democracia plena. Cfr. THE ECONOMIST, "Uruguay y Costa Rica, entre las democracias más plenas del mundo", publicado el 9 de enero de 2019, visible en el link: https://www.dw.com/es/the-economist-uruguay-y-costa-rica-entre-las-democracias-m\%C3\%A1s-plenasdel-mundo/a-47017993-0

${ }^{14}$ Al respecto, véase a Moreno Álvarez, Jesús Al. (2018). El cambio electoral. Votantes, encuestas y democracia en México, México, Fondo de Cultura Económica, p. 99.

${ }^{15}$ Cfr. ASOCIACIÓN DE INTERNET MX, "15 Estudio sobre los Hábitos de los Usuarios de Internet en México 2019", publicado el 13 de mayo de 2019, visible en el link https://www.asociaciondeinternet.mx/es/component/remository/Habitos-de-Internet/15-Estudio-sobrelos-Habitos-de-los-Usuarios-de-Internet-en-Mexico-2019-version-publica/lang,es-es/?Itemid=
} 


\section{López R./ Impacto de las TIC en el modelo de organización electoral mexicano}

suficiente para la protección efectiva de los derechos político-electorales ante los impactos de las nuevas tecnologías?

Formular tales interrogantes, de entrada, es importante porque, como bien lo aduce Sánchez Morales, el ejercicio de los derechos político-electorales de las y los ciudadanos constituye la columna vertebral del ejercicio de las libertades de las personas en el régimen de la democracia representativa; ${ }^{16}$ de ahí que dicho ejercicio, para ser efectivo, debe realizarse con absoluto apego al principio de certeza en materia electoral a fin de evitar la incertidumbre, confusión o afectación que, eventualmente, pudiera generar el impacto de las nuevas tecnologías en los derechos político-electorales. La observancia del principio de certeza es de tal importancia (sin decir que sea el único) que, como lo señalan voces calificadas, repercute en la totalidad de la función electoral, alcanzando la función de aplicación normativa de las autoridades electorales, la función de creación normativa del legislador y la propia de los partidos políticos. ${ }^{17}$

Por tanto, debe tenerse presente la aseveración de Coronado Hernández, en el sentido de que no es suficiente tener contemplados los derechos en una Constitución, sino que, además, es imprescindible contar con los mecanismos de protección, de difusión y conocimiento; como ocurrió -tardíamente-, con los derechos político-electorales del ciudadano en nuestro país, mismos que fueron tutelados jurisdiccionalmente hasta 1996, cuando se elevó a rango constitucional el juicio para su protección. ${ }^{18}$

\section{Aproximaciones de respuestas a los cuestionamientos planteados}

Algunos sucesos del año 2018 en el ámbito electoral nacional permitirán, más adelante, intentar dar aproximaciones de respuestas a los planteamientos formulados en torno a los efectos que genera el empleo de las TIC para el ejercicio de los derechos político-electorales y los derechos con los que guardan estrecha vinculación.

De entrada, en materia de candidaturas independientes, se utilizó la aplicación móvil (app) para la obtención más rápida y certera del apoyo ciudadano a las y los aspirantes, así como para la verificación expedita de la autenticidad de las credenciales de elector. No obstante, en el caso concreto de Jaime Heliodoro Rodríguez Calderón, "El Bronco", el Tribunal Electoral del Poder Judicial de la Federación (TEPJF) determinó la existencia de

${ }^{16}$ Cfr. Sánchez Morales, J. (2018). La reelección legislativa y de ayuntamientos en México, México, Tirant lo Blanch, p. 91.

${ }^{17}$ Orozco Henríquez, J. J. (2003). Isonomía, Revista de Teoría y Filosofía del Derecho, "Consideraciones sobre los principios y reglas en el derecho electoral mexicano", núm. 18, México, Instituto Tecnológico Autónomo de México, abril de 2003, p. 141, citado por Astudillo Reyes, C. I. (2019). en Estudios Electorales, México, Tirant lo Blanch, pp. 174 y 175.

${ }^{18}$ Cfr. Coronado Hernández, L. E. (2019). Marco histórico actual, "Los derechos político-electorales en México", 2a. ed., México, Flores Editor y Distribuidor, 2019, pp. XXVII, 88 y 89. Destacar la importancia de los derechos político-electorales no es un tema menor; esto, en virtud de que los mismos están orientados a posibilitar que las y los ciudadanos tomen parte de los asuntos más relevantes de su país, bajo los correspondientes parámetros constitucionales y legales. Al respecto, véase a Astudillo Reyes, C. I. (2018). El derecho electoral en el Federalismo Mexicano, México, Secretaría de Gobernación, Secretaría de Cultura, Instituto Nacional de Estudios Históricos de las Revoluciones de México e Instituto de Investigaciones Jurídicas de la UNAM, p. 101. 


\section{López R. / Impacto de las TIC en el modelo de organización electoral mexicano}

afectaciones al derecho político-electoral del voto en su vertiente pasiva, al derecho humano a una adecuada defensa (debido proceso), al derecho constitucional de las personas que pretenden postular una opción política más en la contienda electoral, así como a los principios de equidad, imparcialidad, legalidad y certeza en el procedimiento de verificación de apoyos ciudadanos.

Lo anterior, en razón de que los folios contenidos en el sitio de Internet del INE que amparaban el registro de apoyo ciudadano no contenían las causas de inconsistencias que debían subsanarse, las cuales se daban a conocer a los aspirantes hasta que comparecían ante la citada autoridad administrativa electoral; aunado a la negativa de esta última de revisar los apoyos de la etapa preliminar solicitados por el otrora candidato ciudadano a la Presidencia de la República.

Como consecuencia, a fin de garantizar el derecho de participación política, la referida autoridad jurisdiccional electoral, en plenitud de jurisdicción, reconoció la candidatura del ciudadano en comento. ${ }^{19}$

Por otro lado, es importante señalar que, de forma negativa, las nuevas tecnologías han sido utilizadas con fines antijurídicos como lo fue la oferta de venta en el portal de internet de Amazon y MercadoLibre de la base de datos correspondiente al Listado Nominal de Electores del 2015, lo que, si bien, a decir de las autoridades electorales competentes, logró asegurarse e impedirse su comercialización, ${ }^{20}$ lo cierto es que dicho listado se tornó cuestionable y se expusieron datos personales de 93, millones 424 mil 710 registros ciudadanos, comprometiéndose un derecho humano fundamental como lo es el relativo a la protección de datos personales, el cual debe ser replanteado de cara a la era digital. ${ }^{21}$

Como reacción, se tomaron medidas para la debida protección de datos personales, y se multó a los institutos políticos involucrados por el uso indebido de la Lista Nominal y su divulgación, así como a determinados ciudadanos por incumplir su obligación de salvaguardar y preservar la inviolabilidad sobre la confidencialidad de la información inherente al Padrón y Lista Nominal. Es de subrayarse que, situaciones similares, se han

\footnotetext{
${ }^{19}$ Sobre el particular, véase la sentencia emitida por la SALA SUPERIOR DEL TEPJF en los expedientes SUP-JDC186/2018 y su acumulado SUP-JDC-201/2018, de 9 de abril de 2018. Consultable en el link https://www.te.gob.mx/Informacion_juridiccional/sesion_publica/ejecutoria/sentencias/SUP-JDC-01862018.pdf

${ }^{20}$ Para mayor referencia, consúltese Instituto Nacional Electoral, Central Electoral, "INE interpone denuncia por uso indebido de la Lista Nominal, aseguran base de datos y se impide su comercialización", publicado el 7 de octubre de 2018, disponible en el link https://centralelectoral.ine.mx/2018/10/07/ine-interponedenuncia-uso-indebido-la-lista-nominal-aseguran-base-datos-se-impide-comercializacion/. "Ya no debe salir el Padrón del INE", artículo de Benito Nacif, publicado en el Universal, visible en el link https://centralelectoral.ine.mx/2018/10/23/ya-no-salir-padron-del-ine-articulo-benito-nacif-publicadouniversal/

${ }^{21}$ Sobre el particular, véase a Ana Paula Rumualdo, quien acertadamente advierte que la facilidad, así como la continuidad con la que se recolectan datos personales en las tecnologías usables causa preocupación y resignación, pero en pocas ocasiones se habla de cómo replantear el concepto de privacidad, de cara a la era digital. Cfr. RUMUALDO, Ana Paula, Letras Libres, "El discreto encanto de la invasión tecnológica", México, 23 de febrero de 2017, consultable en el link https://www.letraslibres.com/espana-mexico/ciencia-ytecnologia/el-discreto-encanto-la-invasion-tecnologica
} 


\section{López R. / Impacto de las TIC en el modelo de organización electoral mexicano}

presentado en 2003, 2009, 2014, 2016 y 2017, implementándose medidas para contener el uso indebido de datos en 2013 y 2016 las que, hasta ahora, han sido útiles, pero insuficientes. ${ }^{22}$

En similar tenor, las redes sociales también se han usado como medios para socializar, exponencialmente, fake news o noticias falsas cuyos efectos, potencialmente, comprometen el ejercicio efectivo de los derechos político-electorales (particularmente en la intención y emisión del voto y los derechos fundamentales con ellos vinculados, la integridad de los procesos electorales, así como la credibilidad de las instituciones electorales. ${ }^{23}$ Conforme a datos de la plataforma www.verificado.mx, proyecto integrado con la alianza de 60 medios de comunicación que incluyó diarios, líderes de opinión, universidades y organizaciones civiles con la finalidad de frenar la desinformación durante el proceso electoral 2017-2018, los periodistas desmintieron alrededor de 400 informaciones que resultaron ser falsas.

La reacción institucional, en la etapa avanzada del proceso electoral concurrente 20172018, fue que el INE estableciera alianzas con Facebook, Twitter y Google para combatir la desinformación, así como sus efectos perniciosos.

También, en contravención de los derechos políticos-electorales, ciertas tecnologías (celulares, dispositivos electrónicos de comunicación, grabación o filmación) se han empleado como instrumentos para dejar constancia del sentido del sufragio, cuando las y los ciudadanos son presionados o coaccionados para votar en favor de personas ajenas que no representan la libre voluntad del elector. ${ }^{24}$

Adicionalmente, el internet y los espacios digitales, se han empleado para reproducir la violencia política en razón de género que obstaculiza el ejercicio efectivo de los derechos político-electorales, sobre todo, de las mujeres. De hecho, se afirma que “(...) La violencia relacionada con las tecnologías contra las mujeres en México ha ido en aumento y se coloca como un tema de preocupación pública cada vez con más fuerza (...)".25

\section{A manera de conclusiones}

A partir de lo narrado, se plasman las siguientes ideas generales, a modo de conclusiones.

\footnotetext{
22 Para mayor abundamiento, véase las fuentes referidas en la nota 20.

${ }^{23}$ Según el informe "Libertad en la Red 2017: Manipulación de redes sociales para socavar la democracia", de la Organización no gubernamental Freedom House, al menos 18 países vieron afectadas sus elecciones entre los años 2016 y 2017 por la proliferación de noticias falsas online. Cfr. LA NACIÓN, "Fake news. Una alerta para el sistema democrático", publicado el 7 de octubre de 2018, en línea https://www.lanacion.com.ar/2178565-fake-news-una-alerta-sistema-democratico

${ }^{24}$ Así se reconoce en la exposición de motivos de la iniciativa con proyecto de decreto por el que, entre otras cuestiones, se adiciona una fracción VIII Bis al artículo 7 de la Ley General en Materia de Delitos Electorales. Véase CÁMARA DE DIPUTADOS, Gaceta Parlamentaria, año XXI, número 5108-III, 6 de septiembre de 2018, consultable en el link http://gaceta.diputados.gob.mx/Gaceta/64/2018/sep/20180906-III.html\#Iniciativa14 ${ }^{25}$ Cfr. LUCHADORAS MX et al., Informe para la relatora sobre Violencia contra las Mujeres Ms Dubravka Simonovic, "La violencia en línea contra las mujeres en México", p. 12. Conforme al Módulo sobre Ciberacoso 2015 del INEGI (único registro nacional), recogidos en este Informe, al menos 9 millones de mexicanas han sido víctimas de ciberacoso. En línea, consultable en el link https://luchadoras.mx/wpcontent/uploads/2017/12/Informe_ViolenciaEnLineaMexico_InternetEsNuestra.pdf
} 
López R. / Impacto de las TIC en el modelo de organización electoral mexicano

Primera. Las TIC constituyen un componente inseparable de nuestro entorno económico, político, jurídico, cultural y social, situación que ha implicado una nueva forma de relacionarnos y de vivir en sociedad con profundas transformaciones en distintos ámbitos de la actividad humana.

Segunda. En el ámbito jurídico-electoral, particularmente en nuestro modelo de organización electoral nacional, las TIC se utilizan en procedimientos electorales como herramientas para materializar derechos político-electorales y los derechos con ellos vinculados, facilitando la labor constitucional y legal de las autoridades encargadas de la administración electoral de nuestro país, maximizando el empleo de recursos requeridos para tal fin.

Tercera. No obstante los efectos positivos (maximización de recursos humanos y materiales, reducción de tiempos y labor más eficiente y rápida por parte de las autoridades electorales, entre otras), que se observan con el uso de las TIC para efectos de materialización de los derechos político-electorales y los derechos con los que guardan estrecha relación; con dicho empleo, también pueden generarse efectos negativos (afectaciones a determinados derechos político-electorales, al debido proceso, a principios rectores de la función electoral y uso para fines antijurídicos tales como reproducción de violencia política en razón de género y difusión de noticias falsas, por citar solo algunos ejemplos), que llegan a condicionar el ejercicio efectivo de los multicitados derechos, según lo muestran los hechos descritos en el apartado 3.

Cuarta. Consecuentemente, es preciso conocer, comprender y regular (con la debida oportunidad y formalidad), los efectos negativos de referencia, a fin de implementar acciones concretas dirigidas a minimizar riesgos y garantizar los derechos políticoelectorales y los derechos humanos con ellos vinculados, así como los principios de certeza jurídica, transparencia y rendición de cuentas que exige el modelo de organización electoral mexicano.

Quinta. Lo anterior invita a explorar, entre otras acciones relevantes, la necesidad de tomar las previsiones para que las instituciones electorales puedan accionar antes que reaccionar; y la necesidad de internalizar en nuestra democracia constitucional mecanismos de seguimiento y prevención a los impactos que deriven del uso de las TIC en los procedimientos electorales que se implementen para materializar derechos políticoelectorales y los derechos con los que guardan íntima conexión, todo lo cual deberá reflejarse en una clara, sencilla y sólida legislación, comprensible y al alcance de todos, sobre todo, de la ciudadanía; y robustecerse mediante buenas prácticas institucionales, así como corresponsabilidad ética en el uso de las TIC.

Sexta. Finalmente, considerar la idea de García Barrera en el sentido de que debe ser el derecho el que, en medio de la vorágine tecnológica, provea los valores de seguridad jurídica y justicia porque, en efecto, los miembros de una comunidad regulada por el derecho deben saber, de cara al avance científico, qué pueden esperar, cómo lo pueden usar para su desarrollo y cómo pueden evitar que sus intereses legítimos se vean atropellados. Es decir, el derecho debe constituirse en una herramienta fundamental para 


\section{López R. / Impacto de las TIC en el modelo de organización electoral mexicano}

atenuar los impactos negativos de los cambios tecnológicos y anticipar el camino para que se desenvuelvan con frutos positivos para la colectividad. ${ }^{26}$

$Y$ en esa idea, necesariamente debe tener cabida la opinión de Nohlen sobre la arquitectura institucional que se necesita para hacer frente a los cambios tecnológicos de los tiempos que corren, esto es, se necesita una arquitectura institucional que se adecue al contexto, un diseño institucional, administrativo y jurisdiccional que corresponda a los desafíos puntuales y variantes de organizar elecciones libres y honestas. ${ }^{27}$ Cuestión no menor considerando que, como efectivamente lo refiere Cynthia Ramírez “(...) la tecnología no es ética, ni justa, ni buena, ni nada: la tecnología es lo que nosotros ponemos en ella, y si queremos que el mundo se beneficie realmente de esta nueva revolución, la tecnología no lo hará por sí misma". ${ }^{28}$

\section{Fuentes de consulta}

ASOCIACIÓN DE INTERNET MX. (13 de mayo de 2019). “15 Estudio sobre los Hábitos de los Usuarios de Internet en México 2019". Recuperados de https://www.asociaciondeinternet.mx/es/component/remository/Habitos-deInternet/15-Estudio-sobre-los-Habitos-de-los-Usuarios-de-Internet-en-Mexico2019-version-publica/lang,es-es/?/temid=

Astudillo Reyes, C. I. (2019). Estudios Electorales, México, Tirant Lo Blanch.

Astudillo Reyes, C. I. (2018). El derecho electoral en el Federalismo Mexicano, México, Secretaría de Gobernación, Secretaría de Cultura, Instituto Nacional de Estudios Históricos de las Revoluciones de México e Instituto de Investigaciones Jurídicas de la UNAM.

BBC MUNDO. (30 de octubre de 2017). "Sophia, la robot que tiene más derechos que las mujeres en Arabia Saudita". Recuperado de https://www.bbc.com/mundo/noticias41803576

CÁMARA DE DIPUTADOS, Gaceta Parlamentaria, año XXI, número 5116-II, 18 de septiembre de 2018. http://gaceta.diputados.gob.mx/Gaceta/64/2018/sep/20180918II.htmI\#Iniciativa4

${ }^{26}$ Cfr. García Barrera, M. E. (2008). Derecho de las nuevas tecnologías, México, Universidad Nacional Autónoma de México, pp. XI y XII.

${ }^{27}$ Sobre el particular, véase Nohlen, D. (2016). Principio mayoritario, jurisdicción constitucional e integridad electoral. Tres ensayos, México, Universidad Nacional Autónoma de México, Instituto de Investigaciones Jurídicas e Instituto de Estudios Constitucionales del Estado de Querétaro, p. 71.

${ }^{28}$ Cfr. Ramírez, C. (2019). ¿Quién va a exigirle cuentas a la tecnología cuando todos estemos ocupados usándola?, Letras Libres, Recuperado de https://www.letraslibres.com/mexico/ciencia-y-tecnologia/quienva-exigirle-cuentas-la-tecnologia-cuando-todos-estamos-ocupados-usandola 
López R. / Impacto de las TIC en el modelo de organización electoral mexicano

Astudillo Reyes, C. I. (2018). Gaceta Parlamentaria, año XXI, número 5108-III. Recuperado de http://gaceta.diputados.gob.mx/Gaceta/64/2018/sep/20180906III.htmI\#Iniciativa14

Coronado Hernández, L. E. (2019). Los derechos político-electorales en México. Marco histórico actual, 2a. ed., México, Flores Editor y Distribuidor.

DIARIO DIGITAL INFORMATE.COM.MX (28 de febrero de 2018). "Definir uso de voto electrónico, llama Consejero Electoral a Legislativo". Recuperado de https://www.informate.com.mx/nacionales/definir-uso-de-voto-electronico-llamaconsejero-electoral-a-legislativo.html

Díaz Naranjo, F. (1 de julio de 2019), Fortalezas y debilidades de la votación electrónica, en La Silla Rota. Recuperado de https://lasillarota.com/opinion/columnas/fortalezas-ydebilidades-de-la-votacion-electronica/294176

EL ECONOMISTA (26 de junio de 2018). "7 acciones de Twitter para las elecciones del 1 de julio en México". Recuperado de https://www.eleconomista.com.mx/tecnologia/7acciones-de-Twitter-para-las-elecciones-del-1-de-julio-en-Mexico-201806260066.html

García Barrera, M. E. (2008). Derecho de las nuevas tecnologías, México, Universidad Nacional Autónoma de México.

Garita Quesada, M. E. "Las redes sociales como instrumentos de poder: su influencia en la toma de decisiones". Recuperado de http://www.kerwa.ucr.ac.cr/bitstream/handle/10669/73325/Art\%C3\%ADculoLas\%20redes\%20socialessu\%20poder\%20influenciador\%20en\%20la\%20toma\%20de\%20desiciones\%20.pdf? sequence=1\&isAllowed=y

Hacking, I. (2018). La estructura de las revoluciones científicas, Ensayo preliminar, Kuhn, Thomas S., 4a. ed., trad. de Carlos Solís Santos, México, Fondo de Cultura Económica, 2013.

Instituto Nacional Electoral (5 de febrero de 2018). Central Electoral, "Facebook e INE anuncian colaboración para elecciones". Recuperado de https://centralelectoral.ine. $m x / 2018 / 02 / 05 /$ facebook-e-ine-anunciancolaboracion-para-elecciones/

Instituto Nacional Electoral (8 de abril de 2018). Central Electoral, "Colaboran INE y Google para mantener informada a la ciudadanía sobre el Proceso Electoral". Recuperado 
López R. / Impacto de las TIC en el modelo de organización electoral mexicano

de https://centralelectoral.ine. $m x / 2018 / 04 / 08 / c o l a b o r a n-i n e-y$-google-paramantener-informada-la-ciudadania-sobre-el-proceso-electoral/

Instituto Nacional Electoral (2016). Estrategia Nacional de Cultura Cívica 2017-2013 (versión ejecutiva), México.

Instituto Nacional Electoral, Acuerdos INE/CG243/2019 e INE/CG432/2019, Repositorio documental. https://repositoriodocumental.ine.mx/xmlui/discover?query=INE\%2FCG243\%2F20 $19 \&$ scope $=\% 2 F$ https://repositoriodocumental.ine.mx/xmlui/handle/123456789/112647

Instituto Nacional Electoral (8 de abril de 2018). Central Electoral, "INE interpone denuncia por uso indebido de la Lista Nominal, aseguran base de datos y se impide su comercialización". Recuperado de https://centralelectoral.ine.mx/2018/10/07/ineinterpone-denuncia-uso-indebido-la-lista-nominal-aseguran-base-datos-se-impidecomercializacion/.

Instituto Nacional Electoral (23 de octubre de 2018). Central Electoral, "Ya no debe salir el Padrón del INE". Recuperado de https://centralelectoral.ine.mx/2018/10/23/ya-nosalir-padron-del-ine-articulo-benito-nacif-publicado-universal/

Instituto Nacional Electoral (16 de diciembre de 2019). Central Electoral, "Aprueba INE Lineamientos para el voto electrónico en elecciones de Coahuila e Hidalgo 2020". Recuperado de https://centralelectoral.ine.mx/2019/12/16/aprueba-inelineamientos-voto-electronico-elecciones-coahuila-e-hidalgo-2020/

Keane, J. (2019) La nueva era de la revolución de las máquinas, Letras Libres, trad. de Ricardo Dudda, México. Recuperado de https://www.letraslibres.com/espanamexico/revista/la-nueva-era-la-revolucion-las-maquinas

LA NACIÓN (2018) “Fake news. Una alerta para el sistema democrático". Recuperado de https://www.lanacion.com.ar/2178565-fake-news-una-alerta-sistema-democratico

LUCHADORAS MX et al. (2017). La violencia en línea contra las mujeres en México, Informe para la relatora sobre Violencia contra las Mujeres Ms Dubravka Simonovic, Recuperado de https://luchadoras.mx/wpcontent/uploads/2017/12/Informe_ViolenciaEnLineaMexico_InternetEsNuestra.pd $f$

Moreno Álvarez, J. A. (2018). El cambio electoral. Votantes, encuestas y democracia en México, México, Fondo de Cultura Económica. 
López R. / Impacto de las TIC en el modelo de organización electoral mexicano

Nohlen, D. (2016). Principio mayoritario, jurisdicción constitucional e integridad electoral. Tres ensayos, México, Universidad Nacional Autónoma de México, Instituto de Investigaciones Jurídicas e Instituto de Estudios Constitucionales del Estado de Querétaro.

Orozco Henríquez, J. J. (2003). Consideraciones sobre los principios y reglas en el derecho electoral mexicano, Isonomía, Revista de Teoría y Filosofía del Derecho, núm. 18, México, Instituto Tecnológico Autónomo de México, abril de 2003, p. 141, citado por Astudillo Reyes, César Iván, en Estudios Electorales, México, Tirant lo Blanch, 2019, pp. 174 y 175.

PARAMETRÍA, Investigación estratégica, Análisis de Opinión y Mercado, "Apoyan voto electrónico", Recuperado de http://www.parametria.com.mx/carta_parametrica.php?cp=5112

Ramírez, C. (2019). ¿Quién va a exigirle cuentas a la tecnología cuando todos estemos ocupados usándola?, Letras Libres, México. Recuperado de https://www.letraslibres.com/mexico/ciencia-y-tecnologia/quien-va-exigirlecuentas-la-tecnologia-cuando-todos-estamos-ocupados-usandola

Rumualdo, A. P. (2017). El discreto encanto de la invasión tecnológica, Letras Libres, México. Recuperado de https://www.letraslibres.com/espana-mexico/ciencia-ytecnologia/el-discreto-encanto-la-invasion-tecnologica

Sánchez Morales, J. (2018). La reelección legislativa y de ayuntamientos en México, México, Tirant lo Blanch.

THE ECONOMIST (9 de enero de 2019). "Uruguay y Costa Rica, entre las democracias más plenas del mundo". Recuperado de https://www.dw.com/es/the-economisturuguay-y-costa-rica-entre-las-democracias-m\%C3\%A1s-plenas-del-mundo/a47017993-0

Tribunal Electoral Del Poder Judicial De La Federación, Sentencia SUP-JDC-186/2018 y su acumulado SUP-JDC-201/2018. Recuperado de https://www.te.gob.mx/Informacion_juridiccional/sesion_publica/ejecutoria/sente ncias/SUP-JDC-0186-2018.pdf 